\title{
KISA İMPLANTLARIN 19 AYLIK GERİYE DÖNÜK KLİNİK BAŞARILARININ DEĞERLENDİRİLMESİ
}

\author{
THE SUCCESS RATES OF SHORT IMPLANTS IN A 19 MONTHS \\ RETROSPECTIVE EVALUATION
}

\author{
Dr. Dt. Işıl Damla ŞENER YAMANER*
}

Makale Kodu/Article code: 4109

Makale Gönderilme tarihi: 11.06 .2019

Işıl Damla Şener Yamaner: ORCID ID: 0000-0002-4790-6542

Kabul Tarihi: 23.10.2019

DOI : $10.17567 /$ ataunidfd.637076

\section{öz}

Amaç: Bu çalışmanın amacı 10 mm'nin altında kemik yüksekliğine sahip bölgelerde yerleştirilen kısa implantların ortalama 19 aylık takip süresinde, implant klinik başarısının araştıııması ve implant çevresi marjinal kemik kaybının implantın; lokasyonuna, kron/ implant oranına ve hastanın; cinsiyeti, yaşı ve sigara kullanımı gibi parametrelere göre değerlendirilmesidir.

Gereç ve Yöntem: Bu çalışmada; yaşları 20-82 arasında değișen 64 hastaya toplamda 101 adet implant yerleștirildi. İmplantlar 10 hafta iyileşme sürecini takiben yüklendiler. Marjinal kemik kayıpları başlangıç ve ortalama 19 ay sonrasında ölçüldü. İmplant çevresi marjinal kemik kaybı; implant ve hastaya bağlı parametrelere göre değerlendirildi. Ayrıca klinik takip süresi sonundaki yaşam ömürleri hesaplandı.

Bulgular: Çalışmamızda 19 aylık takip süresinde implantlarda ki başarı oranı \%98 dir. İmplantların takip süresi içerisindeki ortalama marjinal kemik kaybı 0,33 $\pm 0,19 \mathrm{~mm}$ olarak bulundu. Kısa implantların kron/implant oranı ile hastanın yaşı ve sigara kullanımının marjinal kemik kaybına etkisi istatistiksel olarak anlamlı bulundu. Buna karşın hastanın cinsiyetinin marjinal kemik kaybına etkisi istatiksel olarak anlamlı tespit edilmedi.

Sonuç: Bu kısa dönem takip çalışması standart uzun dental implantların uygulanamadığı vakalarda kısa dental implantlantların kullanımının ortalama 19 aylık dönemde başarılı olduğunu tespit etmiştir. Ancak daha kesin verilere ulaşabilmek için uzun dönem takip çalışmaları gerekmektedir.

Anahtar Kelimeler: dental implant, panoramik radyografi, başarı.

\section{ABSTRACT}

Aim: The aim of this study is the evaluation of the success rate of short implants in patients who have less than $10 \mathrm{~mm}$ alveolar bone in posterior regions of maxilla and mandible in average 19 months follow-up time. And evaluation of the marginal bone loss around implants according to patient related parameters as smoking, age, gender and implant related parameters as location and crown/implant ratio.

Materials and Methods: One hundred and one implants were placed in 64 patients and loaded with final restorations after 10 weeks of healing time. Marginal bone loss around implants was determined radiographically at initial and after a mean observation time average of 19 months. The effect of smoking habit, age, gender, implant location and crown/implant ratio on the marginal bone loss was evaluated. The survival rate of the implants was determined.

Results: The overall cumulative survival rate of short implants in 19 months was $98 \%$. The mean marginal bone loss value for the short implants was 0,33 $\pm 0,19 \mathrm{~mm}$. Marginal bone loss was affected by the crown/implant ratio, location, patients' smoking habit and age but not the gender of the patient.

Conclusion: With short dental implants, successful clinical results could be achieved in patients who have less than $10 \mathrm{~mm}$ alveolar bone in posterior regions of maxilla and mandible up to 19 months of short follow-up time. Long term studies are needed for short dental implants.

Key words: dental implant, panoramic radiograph, success

\footnotetext{
Özel Poliklinik, DMR DENT Ağız ve Diș Sağlığı Polikliniği, İstanbul, Türkiye
}

Kaynakça Bilgisi: Şener Yamaner ID.Kısa İmplantların 19 Aylık Geriye Dönük Klinik Başarılarının Değerlendirilmesi. Atatürk Üniv Diş Hek Fak Derg 2020; $30: 66-74$. Citation Information: Sener Yamaner ID. The Success Rates of Short Implants in a 19 Months Retrospectıve Evaluation. J Dent Fac Atatürk Uni 2020; 30: 66-74. 


\section{GİRİŞ}

Osteointegrasyonun tanımı; Branemark tarafından 1977 yılında ortaya konmuştur. Latince "oskemik" ve "integrate-birleşmek" kelimelerinden oluşan osteointegrasyon dental implantların uzun dönem başarısı için şarttır. ${ }^{1}$

Osseointegrasyonu destekleyen yeterli kemik temasını sağlayan standart uzun implantlar, alveol kemiği yüksekliği ve genişliği uygun bireylerde başarıya önemli katkı sağlar. Ancak dişsiz bölgedeki mevcut kemik varlığı $10 \mathrm{~mm}$ nin altında olan bireylerde standart uzun implantların kullanımı ancak ileri cerrahi tekniklerin uygulanımı sonrasında mümkün olabilmektedir. $^{2}$

Günümüzde cerrahi işlem sonrası standart uzun implant uygulanımına alternatif olarak kısa implantlar değerlendirilmektedir. Dişsizliğin giderilmesi amacıyla kullanımı her geçen gün artan implantlardan özellikle kısa implantlarla yapılan tedaviler de artık literatürde yaygın olarak desteklenmektedir. 3, 4-10

Yakın zamanda yayınlanan meta analiz-derleme çalışması sonucuna göre sinüs lifting işlemi sonrası standart uzun implantların kullanıldığı vakalar ile kısa implantların kullanıldığı vakalar karşılaştırıldığında implantların başarı oranı açısından herhangi bir farklılık tespit edilmemiştir. Bununla beraber kısa implant vakalarında komplikasyon oranının belirgin olarak az olduğu da belirtilmiştir. ${ }^{11}$

Kısa implantlarla tedavi edilen vakalar üzerinde yapılan çok sayıda çalışmada benzer olarak komplikasyon oranları düşük bulunmuş, ${ }^{4,6,8}$ implant kayıpları açısından bir farklılık tespit edilmemiş ${ }^{4-10}$ ve marjinal kemik kaybı miktarları da standart olarak kabul edilen uzun implantlardan çok daha az olarak tespit edilmiştir. ${ }^{4,5,7,10}$

Kısa implant kullanımının; atrofik maksillada özellikle ön bölgede kötü estetik sonuçlar oluşturabilmesi, klinik kriterlere uygun olmayan kron /implant oranına neden olabilmeleri nedeniyle plak kontrolünün sağlanamaması, göreceli olarak implantın daha hızlı kaybedilme riski ve kemik-implant kontak bölgesinde rezerve kemik olmadığından marjinal kemik kaybının fazla oluşabileceği gibi öngörülebilir sınırlamaları mevcuttur. ${ }^{12}$

Dental implantların başarı kriterleri; osteointegrasyon, ${ }^{13}$ implantın ağızda kalma oranı, radyografik kemik kaybı miktarı, periimplant dokuda enfeksiyon, implantın hem estetik hem de fonksiyonel olarak başarılı olması ${ }^{14}$ şeklinde özetlenebilir. Dental implant uygulamalarında başarıyı etkileyecek olan risk faktörleri de göz önüne alınması gereken hususlardır. Bu risk faktörleri; hastanın yaşı, cinsiyeti, sistemik durumu, sigara ve/veya alkol kullanımı, implantın özellikleri; sayısı, boyutları, hangi çeneye yapıldığı ve implant yapılan bölgede diş kaybetme nedenleri olarak ifade edilebilir. ${ }^{14-17}$

Sigara kullanan bireylerde; oral hastalıklara yatkınlığın tespit edildiği yapılan çalışmalarda kanıtlanmıştır. ${ }^{18}$ Sigara kullanımı, fibroblast aktivitesi, antikor üretimi, nötrofil fonksiyonu ve enflamatuar mediyator üretimi gibi immün cevap aktivitelerine zarar verir. Sigara içen bireylerde içmeyen bireylere göre daha fazla alveoler kemik yıkımı ve daha fazla diş kaybı olduğu bildirilmiştir. ${ }^{19}$

Biyomekanik olarak; kısa implantlar, kron/ implant oranı ve yüksek oklüzal kuvvetler birlikte değerlendirildiğinde, kısa implantların kullanımında düşük başarı beklenmesine rağmen, oklüzal kuvvetlerin implantın boyundan bağımsız olarak alveolar kemiğin kretal kısmında yoğunlaştığı bildirilmiştir. ${ }^{20}$

İmplant tedavilerinde ortaya çıkan komplikasyonlar "aşırı yükler ve/veya non-aksiyel yükler" gibi uygun olmayan oklüzal kuvvetler sebebiyle oluşabilirler. Bazı klinik raporlar oklüzal travma ile marjinal kemik kaybını ilişkilendirirken, ${ }^{21}$ bazıları oklüzal travmayla ilgili olmadığını belirtmişlerdir. ${ }^{22}$

Ayrıca Esposito ve ark . çalışmasında 20 hastadan 15 adedinin ogmentasyon ve standart implant tedavisi yerine kısa implant tedavisini tercih ettiklerini belirtmiştir. ${ }^{23}$ Bu çalışmanın sonucuda ortaya koymaktadır ki tedavi seçeneği belirlenirken hastanın tercihide en önemli kriterlerden biridir.

Bu çalışmanın amacı 10 mm'nin altında kemik yüksekliğine sahip bölgelerde yerleştirilen kısa implantların ortalama 19 aylık takip süresinde, implant klinik başarısının araştırıması ve marjinal kemik kaybının, implantın; lokasyonuna, kron/ implant oranına ve hastanın; cinsiyeti, yaşı ve sigara kullanımı gibi parametrelere göre değerlendirilmesidir.

\section{MATERYAL VE METOD}

$\mathrm{Bu}$ çalışma kliniğimizde 2015-2017 yılları arasında; total veya parsiyel dişsiz, yaşları 20 ila 82 arası değişen 32 erkek, 32 kadın olmak üzere toplam 64 hastada yapılan 101 dental implant üzerinde klinik olarak yürütüldü.

Çalışmamıza katılan hastaların medikal hikâyeleri alındı. Sistemik olarak sağlıklı, cerrahi 
operasyon riski olmayan, oral hijyen seviyesi yüksek, alkol ve/veya ilaç bağımlılığı olmayan ve altı ay içinde kemoterapi \radyoterapi görmemiş hastalar çalışmaya dahil edildi. Sigara kullanımı kayıt edildi ancak tedavi için kontraendikasyon olarak belirlenmedi.

Büyüme ve gelişme çağı devam eden, implant uygulama sahasında lokal bir enfeksiyon ve çene kemiğinde radyografik ve/veya klinik olarak gözlenen bir patoloji olan ve bruksist hastalar çalışmaya dahil edilmedi.

Çalışmaya dahil edilen hastalar; kısa implant yerleştirilmesi için kemik yüksekliğinin posterior maksilla ve mandibula bölgesinde $10 \mathrm{~mm}$ 'nin altında bulunmakta olması ve implant bölgelerinin diş çekimini takiben $\geq 4$ aylık bir iyileşme sürecini tamamlamış olması kriterlerine göre belirlendiler.

Tüm hastalardan onam formu alındı. Hastalara, cerrahiden 1 saat önce başlamak üzere 5 gün boyunca $500 \mathrm{mg}$ amoksisilin antibiyotik verildi. İmplant cerrahisi lokal anestezi ile çift aşamalı cerrahi protokol uygulanarak aynı cerrah tarafından uygulandı. Hastalara on günlük periyot içinde günde $2 \mathrm{kez} \% 0,1$ klorheksidin ağız gargarası reçete edildi. Hastalar 10 gün sonrası dikiş alınması için geri çağrıldı. Hastalar iyileşme sürecinde geçici restorasyon kullanmadı. Tüm implantlar 10 hafta iyileşme sürecini takiben yüklendiler. Ölçü başlıkları ile polivinil siloksan ölçü maddesi kullanılarak implantların ölçüleri alındı. Tüm hastalara metal destekli seramik sabit protezler yapıldı. Prova safhalarını takiben cam iyonomer siman kullanılarak, yapılan sabit protezler implantların üzerine simante edildi.

Klinik takip ve implantların distal/meziyal kenarlarındaki kemik seviyelerinin değişimlerinin hesaplanabilmesi amacıyla implant yerleştirilmesinin hemen sonrasında ve yükleme sonrası ortalama 19 ay sonra standardize edilmiş dijital panoramik radyograflar (Orthophos XG; Sirona Dental Systems, Bensteim, Germany) elde edildi. Kinik takip sonrası implant başarısı ve marjinal kemik kaybı değerlendirildi.

İmplant başarısı; Buser ve ark. ${ }^{24}$ nın çalışmasında tanımladığı implant başarı kriterleri ile tespit edildi. Bu başarı kriterleri; 1-Devamlı ağrı, yabancı cisim hissi ve/veya disestezi; 2-Süpürasyonla birlikte tekrarlayan periimplant enfeksiyonu; 3-İmplant mobilitesi; ve 4-İmplant çevresinde devamlılık gösteren radyolusent alan varlığı, olarak belirlendi.

Marjinal kemik kaybının tespiti amacıyla tek bir araştırmacı tarafından implant boynundan kemik ile implantın ilk temas noktası arasındaki mesafe ölçüldü.
Radyografilerin distorsiyonu ve anatomik büyütmesinin kalibrasyonu, implantların klinik verileri olan boy değeri ve iki yiv arası standart mesafeleri ile yapıldı. Radyografik görüntü boyutlarının kalibrasyonu için basit matematiksel hesaplama yapıldı. ${ }^{25}$

Hastalar; 0-40 (genç), 40-60 (orta yaş), 60 ve üstü (yaşı) olmak üzere üç ayrı yaş grubunda değerlendirildiler. İmplantlar ise dijital panoramik radyografi üzerinde tek bir araştırmacı tarafından kron/implant oranlarına göre $1,2,3$ ve 4 olmak üzere dört ayrı grup olarak incelendiler.

Kısa implant uygulanan hastalarda marjinal kemik kaybı; implantın lokasyonuna, kron/ implant oranına ve hastanın; cinsiyeti, yaşı ve sigara kullanımı gibi parametrelere göre değerlendirildi.

$\mathrm{Bu}$ çalışmada elde edilen verilerin istatistiksel analizleri için SPSS istatistik programı (Version 15.0, SPSS Inc., Chicago,Illinois, ABD) kullanıldı. Verilerin değerlendirilmesinde tanımlayıcı istatistiksel metotların (ortalama, standart sapma) yanı sıra ikili grupların karşılaştırmasında ANOVA testleri, çoklu grupların karşılaştırılmasında Tukey's analizi yöntemi kullanıldı. Sonuçlar, p<0,05 anlamlılık düzeyinde değerlendirildi. İmplant başarısı ise Kaplan Meier sağ kalım testi ile değerlendirildi.

\section{BULGULAR}

Bu çalışmada yaşları 20 ila 82 arasında değişen 64 hastaya toplamda 101 adet implant yerleştirildi. Çalışmaya katılan 32 adet erkek hastanın yaş ortalaması 54,2 (yaş aralığı 20-76) iken, 32 adet kadın hastanın yaş ortalaması 52,3 (yaş aralığı 21-82) olarak belirlendi (Tablo 1).

Tablo 1. Cinsiyete göre toplam hasta sayısı ve yaş ortalamaları ve sigara alışkanlığı

\begin{tabular}{|c|c|c|c|}
\hline & İMPLANT & $\begin{array}{c}\text { YAŞ } \\
\text { ORTALAMASI }\end{array}$ & $\begin{array}{c}\text { SİGARA } \\
\text { ALIŞKANLIĞI }\end{array}$ \\
\hline ERKEK & 52 & 54,2 & 14 \\
\hline KADIN & 49 & 52,3 & 12 \\
\hline TOPLAM & 101 & 53,2 & 26 \\
\hline
\end{tabular}

Hastalar yaş aralığına göre sınıflandırıldığında; kadınların, \%. 12,5 genç, \% 62,5 orta yaşlı, \% 25 yaşı olarak tespit edilirken, erkeklerin, \% 21,9 genç, $\% 40,6$ orta yaşlı ve \% 37,5 yaşlı olarak tespit edildi.

Sigara kullanmayan hastaların sayısı, kullananlardan daha fazlaydı. Hastaların \% 18,6' sı kadın, \% 
$21,9^{\prime}$ u erkek olmak üzere toplamda $\% 40,6^{\prime}$ sı sigara kullanan bireylerdi. Çalışmadaki kısa implantların \% $40,6^{\prime}$ SI maksillaya, \% 59,4' ü mandibulaya uygulanmıştır.

İmplantların yaşam ömürleri Kaplan-Meier istatistiksel analiz yöntemi ile hesaplanmıştır. Kısa implantların tamamının osteointegrasyou başarılı olmasına rağmen biri erkek biri kadın olmak üzere iki sigara kullanan hastada 2 implant sırasıyla 25 ve 19. aylarında kaybedildi. Her iki implant mobilite ve periimplantitis sebebiyle çıkartıldılar. Tüm implant lardaki ortalama 19 aylık takip süresi içerisindeki başarı oranı \%98 dir (Resim 1).

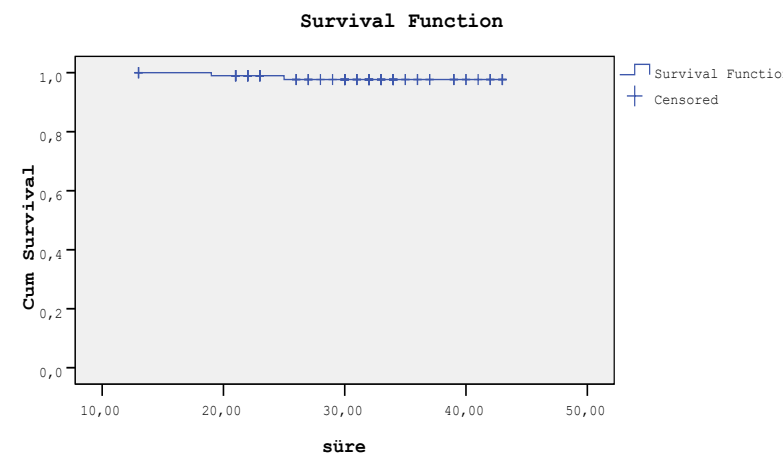

Resim 1. Yaşam ömrü

Toplam 101 adet implantın cerrahiden hemen sonra ve takip süresi sonunda panoramik radyografileri alındı ve alınan radyografiler bilgisayar ortamında değerlendirildi. Başlangıç ve takip sonunda, her implantın mesial ve distal bölgelerindeki marjinal kemik rezorbsiyonu hesaplandı. Elde edilen değerler varyans analizi yöntemi ile istatistiksel olarak değerlendirildi $(p<0,05)$. Takip süresi sonunda ortalama marjinal kemik kaybı tüm implantlarda 0,33 $\pm 0,19 \mathrm{~mm}$ olarak bulundu.

İmplantların takip süresi sonunda marjinal kemik kaybı değerlerinin belirlenen klinik kriterlere göre sonuçları Tablo 2 ve $3^{\prime}$ te gösterilmiştir. İmplantların farklı çenelere yerleştirilmesinin marjinal kemik kaybına etkisi tek yönlü varyans analizi ile değerlendirildi (Tablo 3).

Mandibulaya yerleştirilen implantların 19 ay sonunda ortalama marjinal kemik kaybı değerleri (0.29 $\pm 0,09 \mathrm{~mm}$ ) maksillaya yerleştirilen implantların $(0.39 \pm 0,11 \mathrm{~mm})$ marjinal kemik kaybı değerlerinden istatistiksel olarak anlamlı olarak daha düşük bulundu. ( $p \leq 0.033)$.
Tablo 2. Hasta yaşı cinsiyet ve sigara kullanımın marjinal kemik kaybına etkisi. Tabloda ok işareti Tukey testinde gruplar arası istatiksel anlamlığı belirtmektedir.

\begin{tabular}{|c|c|c|c|c|c|c|c|}
\hline & \multicolumn{3}{|c|}{ Hasta yaşı } & \multicolumn{2}{|c|}{ Cinsiyet } & \multicolumn{2}{|c|}{$\begin{array}{c}\text { Sigara } \\
\text { kullanımı }\end{array}$} \\
\hline & Genç & Orta & Yaşlı & Kadın & Erkek & Var & Yok \\
\hline $\begin{array}{c}\text { Marjinal } \\
\text { kemik } \\
\text { kaybı }\end{array}$ & $\begin{array}{c}0,22 \cdot \\
0,07\end{array}$ & $\begin{array}{c}0,42 \cdot \\
0,11\end{array}$ & $\begin{array}{c}0,31 \cdot \\
0,09\end{array}$ & $\begin{array}{c}0,34 \cdot \\
0,13\end{array}$ & $\begin{array}{c}0,36 \cdot \\
0,12\end{array}$ & $\begin{array}{c}0,53 \\
0,20\end{array}$ & $\begin{array}{c}0,18 \cdot \\
0,03\end{array}$ \\
\hline P değeri & \multicolumn{3}{|c|}{0.007} & \multicolumn{2}{|c|}{0,567} & \multicolumn{2}{|c|}{0,000} \\
\hline
\end{tabular}

Tablo 3. İmplant boyu, lokasyon ve kron/kök oranın marjinal kemik kaybına etkisi

\begin{tabular}{|c|c|c|c|c|c|c|c|c|}
\hline & \multicolumn{2}{|c|}{ Çene } & İmplant boyu & \multicolumn{4}{|c|}{ Kron/kök oranı } \\
\cline { 2 - 8 } & Maksilla & Mandibula & $6 \mathrm{~mm}$ & $8 \mathrm{~mm}$ & $1 / 1$ & $2 / 1$ & $3 / 1$ & $4 / 1$ \\
\hline $\begin{array}{c}\text { Marjinal } \\
\text { kemik } \\
\text { kaybı }\end{array}$ & $0,39 \pm$ & $0,29 \pm$ & $0,34 \pm$ & $0,32 \pm$ & $0,30 \pm$ & $0,34 \pm 0,12$ & $0,50 \pm 0,18$ & $0,87 \pm 0,26$ \\
\hline $\begin{array}{c}\mathrm{P} \\
\text { değeri }\end{array}$ & \multicolumn{2}{|c|}{0,033} & 0,09 & 0,13 & 0,17 & & & \\
\hline
\end{tabular}

İmplant boyunun, marjinal kemik kaybına etkisini değerlendirebilmek için tek yönlü varyans analizi ile 6 ve $8 \mathrm{~mm}$ uzunluktaki implantların marjinal kemik kaybı değerleri karşılaştırıldı. Takip süresi sonunda $8 \mathrm{~mm}$ implantlarda marjinal kemik kaybı $0.32 \pm 0,13 \mathrm{~mm}, 6 \mathrm{~mm}$ implantlarda ise $0.34 \pm 0,14 \mathrm{~mm}$ olarak ölçüldü. Marjinal kemik kaybı değerleri açısından aralarındaki fark istatistiksel olarak anlamlı bulunmamıştır.( $p \geq 0.24)$.

Hastanın yaşı, cinsiyeti ve sigara kullanımının marjinal kemik kaybına etkisini değerlendirebilmek için tek yönlü varyans analizi ile her üç parametre değerlendirildi. İmplantlarda takip süresi sonunda kemik kaybı kadınlarda $0.34 \pm 0,13 \mathrm{~mm}$, erkeklerde ise $0.36 \pm 0,12 \mathrm{~mm}$ olarak ölçüldü. Hastanın cinsiyetinin marjinal kemik kaybına etkisi istatiksel olarak anlamlı tespit edilmemiştir.( $p \geq 0.567)$.Kısa implantlarda takip süresi sonunda marjinal kemik kaybı yaşlı hastalarda $0.31 \pm 0,09 \mathrm{~mm}$, orta yaşı hastalarda $0.42 \pm 0,11 \mathrm{~mm}$ genç hastalarda ise $0.22 \pm 0,07 \mathrm{~mm}$ olarak ölçüldü. Sigara içen hastalarda marjinal kemik kaybı 0.53 $\pm 0,20$ $\mathrm{mm}$ tespit edilirken, sigara içmeyen hastalarda $0.18 \pm 0,03 \mathrm{~mm}$ olarak ölçüldü. Hastanın yaşı ve sigara kullanımın marjinal kemik kaybına etkisi istatiksel olarak anlamlı bulunmuştur.

Kron/implant oranının marjinal kemik kaybına etkisini değerlendirebilmek için tek yönlü varyans analizi ile farklı kron/implant oranlarına sahip implantların marjinal kemik kaybı değerleri karşılaştırıldı. Kısa implantlarda; $1 / 1$ kron/implant oranına sahip implantlarda takip süresi sonunda kemik kaybı $0.30 \pm 0,17 \mathrm{~mm}, 2 / 1$ kron kök oranına sahip 
implantlarda $0.34 \pm 0,12 \mathrm{~mm}, 3 / 1$ kron kök oranına sahip implantlarda $0.50 \pm 0,18 \mathrm{~mm}$ ve $4 / 1$ kron kök oranına sahip implantlarda $0.87 \pm 0,26 \mathrm{~mm}$ olarak ölçüldü. Kron/implant oranının marjinal kemik kaybına etkisi istatistiksel olarak anlamlı bulunmuştur $(p \geq$ 0.002) (Tablo 4).

Tablo 4. Yerleştirilen implantlarda kron/implant oranları

\begin{tabular}{|c|c|c|c|}
\hline KRON/İMPLANT ORANI & \multicolumn{3}{|c|}{} \\
\cline { 1 - 1 } $\mathbf{1 / 1}$ & $\mathbf{2 / 1}$ & $\mathbf{3 / 1}$ & $\mathbf{4 / 1}$ \\
\hline 43 & 34 & 21 & 3 \\
\hline
\end{tabular}

\section{TARTIŞMA}

Aşırı resorbsiyon vakalarında standart implantları kullanabilmek ancak vertikal kemik ogmentasyonu veya sinüs cerrahileri ile mümkün olabilmektedir. ${ }^{26}$

Kısa implantlar, aşırı resorbe maksiller ve mandibuler posterior segmentlerde farkli cerrahi tekniklere alternatif olmuştur. ${ }^{2,20,27-29}$ Mandibuler posterior bölgede, mandibuler alveoler sinir ile kret tepesi arasındaki mesafe yetersiz olduğunda blok kemik grefteleri ya da alveoler distraksiyon tekniği ile yeterli kemik yüksekliği sağlanmaya çalışılmaktadır. Aynı şekilde posterior maksillada sinüs tabanı ile kret tepesi arasındaki mesafe standart uzunluktaki bir implantı yerleştirecek kadar yeterli değilse, açık sinüs lifting tekniği ya da diğer ogmentasyon teknikleri kullanılarak kemik elde edilmeye çalışılmaktadır. Ancak bu tip cerrahi işlemlerin invaziv oluşu sebebiyle yüksek komplikasyon riski ve maliyeti dolayısıyla hem hasta hemde hekim açısından zorluklar yaratmaktadır. Ayrıca ileri cerrahi tekniklerin uygulanmasında klinik başarı açısından hekim tecrübesi ve bilgisi önem kazanmaktadır. ${ }^{11,30-32}$

Literatürde kısa implant tanımı çelişkilidir. Kısa implantları ilk kez 1979 'da Branemark tarafından 7 mm olarak tanımlanmıştır. ${ }^{33}$ Ancak bazı araştırmacılar kısa implantı tanımlarken $10 \mathrm{~mm}$ den kısa olanları, bazıları ise $8 \mathrm{~mm}$ den daha kısa olan implantları "kısa implant" olarak tanımlamıştır. ${ }^{28,34,35}$ Son dönemde kısa implant tanımı bazı çalışmalarda $6 \mathrm{~mm}$ den kısa implant olarak tanımlanmaktadır. ${ }^{36} \mathrm{Bu}$ çalışmada kısa implant tanımı $8 \mathrm{~mm}$.ve altındaki implantlar olarak tanımlanmıştır.

Uzun dönem klinik çalışmalarda implantların sağ kalım oranı klinik başarı açısından önemlidir. Thoma ve ark. ${ }^{37}$ nın EAO çalışma grubu olarak hazır- ladıkları derleme çalışmasında kısa implantların ortalama sağ kalım oranları \%99 olarak tespit edilmiştir. Bu oran, aynı çalışmada tespit edilen $10 \mathrm{~mm}$ ve üzerindeki implantların uzun dönemde ortalama sağ kalım oranları olan \%99,5 değerine oldukça yakındır.

Standart uzun ve kısa implantların ( $\leq 8 \mathrm{~mm}$ ) yaşam ömrünü karşılaştıran 6 adet bir yıllık klinik takip çalışmasında kısa implantlar için yaşam ömrü \%97,01100 arası değişirken çok benzer olarak standart uzun implantlar içinde \%96,70-100 arası tespit edilmiştir. $5,6,8,9,38,39$

Beş yıllık uzun süreli takip çalışmasında ise yine benzer sonuçlarla kısa implantlar için yaşam ömrü \%95,08, standart uzun implantlar içinde \%91,67 olarak tespit edilmiştir. ${ }^{4} \mathrm{Bu}$ çalışmada da benzer olarak tüm implantlardaki ortalama 19 aylık takip süresi içerisindeki başarı oranı \%98 dir.

İmplantların uzun dönem klinik başarısında değerlendirme kriterlerinden en önemlisi marjinal kemik kaybıdır. İmplantın başarısında marjinal kemik kaybı miktarı Albrektsson ve ark. tarafından "marjinal kemik kaybı yüklemenin yapıldığı ilk yıl 1.5 mm'den az olmalıdır" şeklinde tanımlanmıştır. ${ }^{40 .}$

$\mathrm{Bu}$ çalışmanın verileri yapılmış implantların geriye dönük klinik takip sürelerinden elde edilmiş olduğundan dolayı ortalama süre, tüm implantların toplam takip süresini implant sayısına böldüğümüzde 19 ay olarak bulunmuştur. Bu çalışmada ilk 19 ay içerisinde oluşan kemik kaybı, belirtilen bu kemik kaybı değerlerinin altında kalmıştır. Bu açıdan değerlendirildiğinde çalışmadaki kısa implantların erken dönemdeki kemik kayıpları klinik olarak kabul edilebilir limitler içerisinde kalmıştır.

Felice ve ark. ${ }^{4}$ kısa implantlarla yaptıkları 5 yıllık uzun dönem takip çalışmalarında implantların çevresinde ortalama 4,4 mm kemik desteği olduğunu ve bu resorpsiyon ilerledikçe implant kaybı riskinin oldukça yüksek olacağını ifade etmişlerdir. Bundan dolayıda hastaya; cerrahi işlem ve standart uzunluktaki implant tedavisi mi yoksa kısa implant tedavisi mi en iyi tedavi seçeneğidir diyebilmek için 10 yıllık klinik takip sonuçları elde edilmelidir sonucuna varmışlardır.

Bununla beraber bu uzun dönem klinik takip çalışmasında buldukları sonuçlarda oldukça cesaret vericidir. Çalışmada marjinal kemik kayıpları kısa implantlarda, uzun implantlara göre $0,8 \mathrm{~mm}$ daha az tespit edilmiştir. Araştırmacılar kısa implantlardaki kemik kaybı miktarının neden daha az olduğunu açıklamanın zor olduğunu, uzun implantlardaki ogmentasyon işlemleri ile ilgili olabileceğini ifade etmişlerdir. ${ }^{4}$ 
Renouard ve ark. ${ }^{2} 96$ kısa implantı değerlendirdikleri iki yıllık takip çalışmalarında marjinal kemik kaybının ortalama $0,44 \mathrm{~mm}$ olduğunu tespit etmişlerdir.

Kısa implantları değerlendiren klinik çalışmalarda ilk yıl içerisinde oluşan marjinal kemik

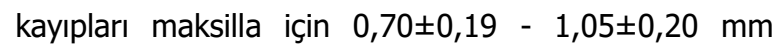

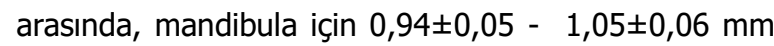
arasındadır. ${ }^{5,6,8,9}$ Çalışmamızda 0,33 $\pm 0,19 \mathrm{~mm}$ olarak tespit edilen marjinal kemik kayıpları çalışmaların değerlerinin altında bulunmuştur. Kısa implant kavramı içerisinde bulunan 4-7 mm arası dental implantların bu çalışmalarda daha yoğun olarak değerlendirilmesi bu sonucun bir nedeni olarak kabul edilebilir.

Koszuta ve ark. ${ }^{41}$ cinsiyetin tek başına implant kayıplarında etkisi olmadığını ancak hasta hormon tedavisi görüyor ise implant tedavisi sırasında etkili olduğunu çalışmalarında belirtmişlerdir. Çalışmamıza katılan hastaların hepsi sağlıklı olduğundan herhangi bir negatif etki tespit edilmemiş ve cinsiyet faktörünün marjinal kemik kaybında etkisi görülmemiştir.

Günümüzde sigara kullanımının; implant başarısı için önemli risk faktörlerinden biri olduğu ve dokuların oksijenlenmesini bozarak yara iyileşmesini olumsuz etkilediği kanıtlanmıştır. Bu çalışmada da kısa implantlarını kaybeden hastalar, sigara kullanıcısı olarak tespit edilmiştir. Önceki çalışmaların sigara kullanımının osteointegrasyonu etkileyerek implant kaybına yol açtığını bildiren sonuçları bu sonucu des- tekler niteliktedir. ${ }^{17,42,43}$ Sigara kullanan bireyler için; yakın zamanda yapılan çalışmalar sigara kullanımının çevre kemiğe zararlı etkilerini belirtmiş ve implant çevresi osteointegrasyonu olumsuz etkilediğini tespit etmişlerdir. ${ }^{44,45}$

Koldsland ve ark. ${ }^{46}$ nın çalışmalarında sigara kullanan periodontal hastalık geçmişi olan bireylerin ortalama $8,4(1,1-16)$ yıl süre içerisinde implant kaybı yaşadıklarını belirten sonuçları diğer çalışmaların sonuçlarını destekleyici niteliktedir.

$\mathrm{Bu}$ çalışmada da sigara kullanan hastalarda marjinal kemik kaybı sigara içmeyen hastalara göre istatistiksel olarak anlamlı olarak yüksek bulunmuştur. Bunun anlamı kısa implant tedavisi olan hastalarda var olan kemik kaybı riskinin sigara kullanımı ile uzun dönemde artabileceğidir.

İmplantların lokasyonu değerlendirildiğinde ise maksillanın mandibulaya kıyasla farklı kemik kalitesi ve daha trabeküler yapısı nedeniyle implant başarısına sınırlandırmalar getirdiği bilinmektedir. Jebreen ve $\operatorname{ark}^{47}$ nın 141 implantla yaptıkları retrospektif çalışmada maksillaya uygulanan implantlarda mandibulaya göre daha fazla kemik kaybı tespit edilmiştir. Bu çalışmada da kısa implantlarla benzer sonuçlar elde edilmiştir.

Bazı çalışmalar kısa implantlarda uygun olmayan kron/implant oranının aşırı yükler sonucunda biyolojik komplikasyonlara yol açabileceğini tespit etmişlerdir. ${ }^{48,49}$

Wang ve ark. ${ }^{50}$ çalışmalarında biyolojik komplikasyon riskinin implant boyundan daha çok kron boyu ile ilgili olduğunu belirtmişlerdir. Bu sonlu elemanlar analizi çalışmasında implant boyunun arttırılması ile kron boyunun azaltılması karşılaştırılmış ve kron boyunun azaltılmasının implant çevresi kemikte stresi belirgin olarak azalttı̆̆ tespit edilmiştir.

Benzer şekilde Marcelo ve ark. ${ }^{51}$ da çalışmalarında kron boyutu arttıkça ve implant boyutu azaldıkça implant yüzeyinde oluşan stresslerin arttığını tespit etmişlerdir. Bununla beraber, Bidez ve Misch protetik kron yüksekliğinin 10 mm'den 20 mm'ye çıkmasının implant üzerindeki kuvveti $\% 100$ artıracağını

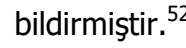

Çalışmamızda da kron/implant oranı arttıkça marjinal kemik kayıp miktarı istatistiksel olarak anlamlı olarak artmıştır. Bu açıdan kısa implantlarda klinik kron/implant oranı arttığı durumlarda implant başarısı daha uzun klinik takip periotlarında değerlendirilmesi gerekmektedir.

\section{SONUÇ}

Çalışmamızda 19 aylık takip süresinde aşağıdaki sonuçlar elde edilmiştir.

1. Tüm implantlarda ki başarı oranı $\% 98$ dir.

2. İmplantların takip süresi içerisindeki ortalama marjinal kemik kaybı 0,33 $\pm 0,19 \mathrm{~mm}$ olarak bulunmuştur.

3. İmplantların takip süresi içerisindeki marjinal kemik kayıplarına; implantın kron/implant oranı ve lokasyonu ile hastanın sigara kullanımının ve yaşının etkisi istatistiksel olarak anlamlıdır. Buna karşın cinsiyetin anlamlı bir etkisi bulunamamıştır.

NOT: Çalışmada herhangi bir yazar, kurum ya da kuruluş ile çıkar çatışması içerisinde bulunmamaktadır. Makale daha önce hiçbir yerde yayınlanmamış ve yayınlanmak üzere işlem görmemektedir 


\section{KAYNAKLAR}

1-Ellingsen JE, Thomsen P, Lyngstadaas SP. Advances in Dental Implant Materials and Tissue Regeneration. Periodontolog 2000 2006; 41:13656.

2-Renouard F, Nisand D. Impact of implant length and diameter on survival rates. Clin Oral Implants Res 2006;17:35-51.

3- Dağ M, Karaçaylı Ü. Dental implantlarda Yapısal ve Yüzey Özellikleri. Atatürk Üniv Diş Hek Fak Derg 2015;25: 119-27.

4-Felice P, Cannizzaro G, Barausse C, Pistilli R, Esposito M. Short implants versus longer implants in vertically augmented posterior mandibles: a randomised controlled trial with 5-year after loading follow-up. Eur J Oral Implantol 2014; 7:359-69.

5-Pistilli R, Felice $P$, Cannizzaro G, Piatelli M, Corvino V, Barausse C, Buti J, Soardi E, Esposito M. Posterior atrophic jaws rehabilitated with prostheses supported by $6 \mathrm{~mm}$ long $4 \mathrm{~mm}$ wide implants or by longer implants in augmented bone. One-year postloading results from a pilot randomised controlled trial. Eur J Oral Implantol 2013; 6:359-72.

6-Pistilli R, Felice P, Piattelli M, Gessaroli M, Soardi E, Barausse C,Buti J, Corvino V. Posterior atrophic jaws rehabilitated with prostheses supported by $\mathrm{x}$ $5 \mathrm{~mm}$ implants with a novel nanostructured calcium-incorporated titanium surface or by longer implants in augmented bone. One-year results from a randomised controlled trial. Eur J Oral Implantol 2013;6:343-57.

7- Esposito M, Pellegrino G, Pistilli $R$, et al. Rehabilitation of posterior atrophic edentulous jaws: prostheses supported by $5 \mathrm{~mm}$ short implants or by longer implants in augmented bone? One-year results from a pilot randomised clinical trial. Eur J Oral Implantol 2011;4:21-30.

8-Esposito M, Barausse C, Pistilli R, Sammartino G, Grandi G, Felice P. Short implants versus bone augmentation for placing longer implants in atrophic maxillae: one-year post-loading results of a pilot randomised controlled trial. Eur J Oral Implantol 2015;8:257-68.
9-Felice $P$, Pistilli R, Barausse C, Bruno V, TrullenqueEriksson A, Esposito $M$. Short implants as an alternative to crestal sinus lift: a 1-year multicentre randomised controlled trial. Eur J Oral Implantol 2015;8:375-84.

10- Cannizzaro G, Felice P, Buti J, Leone M, Ferri $V$, Esposito M. Immediate loading of fixed crossarch prostheses supported by flapless-placed supershort or long implants: 1-year results from a randomised controlled trial. Eur J Oral Implantol 2015;8:27-36.

11-Fan T, Li Y, Deng WW, Wu T, Zhang W. Short implants (5 to $8 \mathrm{~mm}$ ) versus longer implants ( $>8$ $\mathrm{mm}$ ) with sinus lifting in atrophic posterior maxilla: a meta-analysis of RCTs. Clin Implant Dent Relat Res 2017;19: 207-15.

12-Palacios JAV, Garcia J], Caramês JMM, Quirynen M, da Silva Marques DN. Short implants versus bone grafting and standard-length implants placement: a systematic review. Clin Oral Invest 2018; 22:6980.

13. Papaspyridakos $P$, Chen $C$, Singh $M$, Weber HP, Galucci GO. Success Criteria in Implant dentistry: A systematic review. J Dent Res 2012;91:242-8.

14. Misch $C E$, Perel $M L$, Wang $H L$, Sammartino G, Galindo-Moreno P, Trisi P, Steigmann M, Rebaudi A, Palti A, Pikos MA, Schwartz-Arad D, Choukroun J,Gutierrez-Perez JL, Marenzi G, Valavanis DK. Implant success, survival and failure: The International Congress of Oral Implantologists (ICOI) Pisa Consensus Conference. Implant Dent 2008; 17: 5-15.

15. Baqain ZH, Moqbel WY,Sawair FA. Early dental implant failure:risk factors.British J Oral Maxillofac Surg 2012;50:239-43.

16. Misch CE. Contemporary Implant Dentistry. Third edition. Mosby Elsevier 2008:421-621.

17. Eltaş A, Uzun İH, Dündar S, Arslan Malkoç M. Dental İmplant Başarısının ve Hasta Profilinin Değerlendirilmesi: Retrospektif Bir Çalışma. Atatürk Üniv Diş Hek Fak Derg 2013; 21: 1-8.

18. Mallampalli A, Guntupalli KK. Smoking and systemic disease. Clin Occup Environ Med 2006; 5: 173-92. 
19. Van der Velden U, Varoufaki A, Hutter JW, Xu L, Timmerman MF, Van Winkelhoff AJ, Loos BG. Effect of smoking and periodontal treatment on the subgingival microflora. J Clin Periodontol 2003; 30: 603-10.

20-Pierrisnard L, Renouard F, Renault P, Barquinis M. Influence of implant length and bicortical anchorage on implant stress distribution. Clin Implant Dent Relat Res 2003;5:254-62.

21-Blanes RJ. To what extent does the crown-implant ratio affect the survival and complications of implant-supported reconstructions? A systematic review. Clin Oral Implants Res. 2009;20 Suppl 4:67-72.

22- Engel E, Gomez-Roman G, Axmann-Kremar D. Effect of occlusal wear on bone loss and Periotest value of dental implants. Int J Prosthodontics 2001;14: 444-50.

23-Esposito M, Cannizzaro G, Soardi E, Pistilli R, Piattelli M, Corvino V, Felice P. Posterior atrophic jaws rehabilitated with prostheses supported by 6 mm-long, $4 \mathrm{~mm}$-wide implants or by longer implants in augmented bone. Preliminary results from a pilot randomised controlled trial. Eur J Oral Implantol 2012; 5: 19-33.

24. Buser D, von Arx T, ten Bruggenkate $C$, et al. Basic surgical principles with ITI implants. Clin Oral Implants Res 2000; 11(suppl 1): 59-68.

25. Galindo-Moreno P, Leon-Cano A, Monje A, et al. Abutment height influences the effect of platform switching on periimplant marginal bone loss. Clin Oral Implants Res. 2016; 27: 167-73.

26-Villa G, Stavola L, Fincato A, Guida A, Magliano A, Merli M, Polizzi G, Karl M. Short, parallel-walled, conical-connection implants for a broad range of indications in the maxilla and mandible: Retrospective multicenter study with up to 33 months of follow-up. Quintessence Int 2018;49:645-51.

27. Atieh MA, Zadeh H, Stanford CM, et al. Survival of short dental implants for treatment of posterior partial edentulism: a systematic review. Int J Oral Maxillofac Implants 2012;27:1323-31.

28. Lee SA, Lee CT, Fu MM, et al. Systematic review and meta-analysis of randomized controlled trials for the management of limited vertical height in the posterior region: short implants (5 to $8 \mathrm{~mm}$ ) vs longer implants (> $8 \mathrm{~mm}$ ) in vertically augmented sites. Int J Oral Maxillofac Implants 2014;29:108597.
29. Jain N, Gulati M, Garg M, Pathak C. Short implants: new horizon in implant dentistry. J Clin Diagn Res 2016;10:14-17.

30- Esfahrood ZR, Ahmadi L, Karami E, Asqhari S. Short dental implants in the posterior maxilla: a review of the literature. J Korean Assoc Oral Maxillofac Surg 2017;43:70-76.

31-Thoma DS, Cha JK, Jung UW. Treatment concepts for the posterior maxilla and mandible: short implants versus long implants in augmented bone. J Periodontal Implant Sci 2017;47:2-12.

32-Geminiani A, Tsigarida A, Chochlidakis K, Papaspyridakos PV, Feng C, Ercoli C. A metaanalysis of complications during sinus augmentation procedure. Quintessence Int 2017;48:231-240.

33-Tutak M, Smektala T, Schneider K, Golebiewska E, Sporniak-Tutak K. Short dental implants in reduced alveolar bone height: a review of the literature. Med Sci Monit 2013;21:1037-42.

34-Weng D, Jacobson Z, Tarnow D, Hurzeler MB, Faehn $O$, Sanavi $F$ ve ark. A prospective multicenter clinical trial of $3 i$ machined-surface implants: results after 6 years of follow-up. Int J Oral Maxillofac Implants 2003;18:417-23.

35-Telleman G, Raghoebar GM, Vissink A, den Hartog L,Huddleston Slater JJ, Meijer HJ. A systematic review of the prognosis of short $(<10 \mathrm{~mm})$ dental implants placed in the partially edentulous patient. J Clin Periodontol 2011;38: 667-76.

36-Neldam CA, Pinholt EM. State of the art of short dental implants: a systematic review of the literature. Clin Implant Dent Relat Res 2012;14:622-32.

37-Thoma DS, Zeltner M, Hüsler J, Hammerle CHF, Jung RE. EAO Supplement Working Group 4 - EAO CC 2015 Short implants versus sinus lifting with longer implants to restore the posterior maxilla: a systematic review. Clin Oral Impl Res 2015;26:154- 69.

38-Thoma DS, Haas R, Tutak M, Garcia A, Schincaglia $\mathrm{GP}$, Hämmerle $\mathrm{CH}$. Randomized controlled multicentre study comparing short dental implants (6 mm) versus longer dental implants (11-15 mm) in combination with sinus floor elevation procedures. Part 1: demographics and patientreported outcomes at 1 year of loading. J Clin Periodontol2015; 42:72-80. 
39-. Guljé FL, Raghoebar GM, Vissink A, Meijer HJA. Single crowns in the resorbed posterior maxilla supported by either 6-mm implants or by 11 mmimplants combined with sinus floor elevation surgery: A 1-year randomised controlled trial. Eur ] Oral Implantol 2014;7:247-55.

40-Albrerktsson T, Zarb G, Worthington D, Eriksson R. The long term efficiency of currently used dental implants. A review and proposed criteria of success. Int J Oral Maxillofac Implants 1986; 1: 11-25.

41- Koszuta P, Grafka A, Koszuta A, Lopucki M, Szymanska J. Effects of selected factors on the osseointegration of dental implants Prz Menopauzalny 2015;14:184-87.

42. Koldsland OC, Scheie AA, Aass AM. Prevalence of implant loss and the influence of associated factors. J Periodontol 2009;80: 1069-75.

43. Alsaadi G, Quirynen M, Michiles K, Teughels W, Komárek $A$, van Steenberghe D. Impact of local and systemic factors on the incidence of failures up to abutment connection with modified surface oral implants. J Clin Periodontol 2008; 35:51-7.

44-Chambrone L, Preshaw PM, Ferreira JD, Rodrigues JA, Cassoni A, Shibli JA. Effects of tobacco smoking on the survival rate of dental implants placed in areas of maxillary sinus floor augmentation: systematic review. Clin Oral Implants Res 2014;25:408-16.

45-Bezerra Ferreira JD, Rodrigues JA, Piattelli A, Iezzi G, Gehrke SA, Shibli JA. The effect of cigarette smoking on early osseointegration of dental implants: a prospective controlled study. Clin Oral Implants Res 2016; 27:1123-28.

46. Koldsland OC, Scheie AA, Ass AM. Prevalence of implant loss and the influence of associated factors. J Periodontol 2009; 80: 1069-75.

47. Jebreen SE, Khraisat A. Multicenter retrospective study of ITI implant supported posterior partial prosthesis in Jordan. Clin Implant Dent Relat Res. 2007;9:89-93.

48- Sotto-Maior BS, Senna PM, da Silva-Neto JP, de Arruda Nobilo MA, Del Bel Cury AA. Influence of crown-to-implant ratio on stress around single short-wide implants: a photoelastic stress analysis. J Prosthodont 2015;24:52-6.
49-Ramos Verri F, Santiago Junior JF, de Faria Almeida DA, de Oliveira GB, de Souza Batista VE, Marques Honorio $\mathrm{H}$, Noritomi PY, Pellizzer EP. Biomechanical influence of crown-toimplant ratio on stress distribution over internal hexagon short implant: 3-D finite element analysis with statistical test. J Biomech 2015;48:138-45.

50-Wang TM, Wang JS, Chang CF, Lin LD. (2002) Effects of crown-implant height ratio on periimplant bone stress. IADR Abstract, 80th IADR Meeting, San Diego.

51-Marcelo BT, Ana PM, Renata CS, Rodrigues Ricardo FR, Maria GCM. A three-dimensional Finite Element Analysis of the Stress Distribution on Morse Taper Implants Surface. J Prosthodont Res 2013;57, 20612.

52. Bidez MW, Misch CE. Force transfer in implant dentistry: basic concepts and principles. J Oral Implantol. 1992;18:264-74.

\section{Yazışma Adresi}

Dr. Dt. Işıl Damla ŞENER YAMANER

DMR DENT Ağız ve Diş Sağlığı Polikliniği

Levent Mah. Levent Cad.

Beşiktaş-İstanbul

Mail to; isildamlasener@gmail.com

Phone no: 02122703066

Fax no: 02122703068 